\title{
Palma, historiador de 1825
}

Por Alberto Varillas Montenegro 
Realizó sus estudios en la Facultad de Letras y en la Facultad de Derecho y Ciencias Políticas de la Pontificia Universidad Católica del Perú. Es presidente del Patronato de la Casa Museo Ricardo Palma. 


\section{Presentación}

En 1877, el coronel Manuel de Odriozola publicó, dentro de la colección de Documentos Literarios del Perú, un artículo de Ricardo Palma, de carácter histórico, titulado Monteagudo y Sánchez Carrión. En este trabajo Palma sostenía, entre otros puntos, que tanto el asesinato del coronel Bernardo Monteagudo (25 de enero de 1825) cuanto la muerte de José Faustino Sánchez Carrión (2 de junio de 1825) habían sido crímenes políticos.

La opinión pública de América Latina creyó entender que Palma culpaba de la muerte de Monteagudo, gran promotor de la monarquía constitucional, a quienes postulaban para el Perú un régimen de gobierno republicano (es decir, a una Logia republicana o al propio Sánchez Carrión) y de la muerte del republicano Sánchez Carrión a Bolívar que ansiaba para sí un régimen vitalicio (puesto que Sánchez Carrión era la cabeza visible del movimiento republicano y porque con el asesinato de Monteagudo el Libertador había perdido a su único gran operador político).

La polémica desatada estuvo centrada en la muerte de Sánchez Carrión, puesto que aparentemente involucraba a Bolívar en un asesinato, acusación que Palma no había formulado, pero manifestó un interés limitado en el asesinato de Monteagudo. La publicación del trabajo de Palma, quien hacia fines de la década de 1870 se encontraba gozando de uno de sus 
momentos de mayor prestigio literario, originó un escándalo histórico en el cual intervinieron partidarios y detractores de Bolívar venezolanos, colombianos, ecuatorianos, chilenos y, por supuesto, peruanos.

Hoy, casi dos siglos después de la muerte de Monteagudo y Sánchez Carrión cabe estudiar este asunto en forma desapasionada pues se refiere a uno de los más discutidos aunque menos leídos textos del tradicionista peruano. ${ }^{1}$

\section{Palma, historiador de 1825}

A mediados de la década de 1870, Ricardo Palma era un escritor importante y, desaparecidos Pardo y Aliaga (1868) y Segura (1872), el de mayor prestigio en el Perú: ya circulaban las primeras series de sus Tradiciones y no había publicación literaria que no aspirara a engalanar sus páginas con alguna colaboración suya.

En aquel tiempo ya había pasado una década de la publicación del primer trabajo de investigación histórica de Palma, los Anales de la Inquisición de Lima ${ }^{2}$ y la madurez de don Ricardo lo había encaminado de manera progresiva hacia el género que le dio grandeza, la tradición. Sin embargo, Palma seguía siendo un gran aficionado a la historia y ello lo condujo a preparar cuando menos dos trabajos con ese carácter:

I El presente trabajo es una versión corregida y aumentada del presentado en las jornadas denominadas Re-visión de las Tradiciones, convocadas anualmente por el Instituto Ricardo Palma de la URP. Fue publicado en Aula Palma XI (Lima, Universidad Ricardo Palma, 2012), págs. [193-220].

2 Ricardo Palma, Anales de la Inquisición de Lima. Estudio histórico. Lima, Tipografía de Aurelio Alfaro, 1863. Parte del trabajo había sido publicado anteriormente en Valparaíso, en 1861, en la Revista de Sud América, de la cual Palma fue asiduo colaborador. 
sus Reminiscencias de la administración del coronel José Balta y el artículo que motiva los presentes apuntes: Monteagudo y Sánchez Carrión. Páginas de la historia de la independencia, por Ricardo Palma. [En:] Manuel de Odriozola, Colección de Documentos Literarios del Perú. Lima, Imprenta del Estado,1877. Tomo xi, págs. 395/414.

Se sabe de otras dos ediciones de este último trabajo: la primera es mencionada por Palma en el prólogo a Cachivaches (Lima, 1900): el autor informa que el artículo había sido publicado separadamente, como folleto in- $4^{\circ}$, de 175 por $105 \mathrm{~mm}$., pero solo Gabriel René Moreno declara haber tenido un ejemplar a la vista; la segunda edición aparece en la Sexta Serie de Tradiciones publicada en $1883^{3}$ y en ella se reproduce tanto el artículo de Palma (Monteagudo y Sánchez Carrión, fechado en Lima el 20 de octubre de 1877) cuanto varios otros textos relacionados con la polémica que su publicación suscitó. ${ }^{4}$ Como el artículo de Palma no aparece publicado en las distintas ediciones de sus Tradiciones, ha resultado escasamente leído.

El artículo que hoy nos ocupa debe haber sido preparado entre los primeros meses y octubre de $1877^{5}$ y sin duda fue el más

3 Tradiciones por Ricardo Palma. Miembro correspondiente de la Real Academia Española. Sexta serie. Lima, Imprenta del Universo de Carlos Prince, 1883.

4 En esta edición se incluyen las respuestas de Palma a las intervenciones que en esta agria discusión tuvieron en su contra Mariano Felipe Paz Soldán y Francisco Javier Mariátegui (de 20 de marzo y 16 de abril de 1878, respectivamente), un nuevo artículo de Palma sobre las impugnaciones colombianas (5 de noviembre de 1878), cartas de venezolano José Félix Soto y de Palma a Simón Camacho Bolívar (noviembre de 1878) y un interesante resumen de la polémica preparado por el propio Palma (5 de diciembre de 1883). Como puede advertirse, la polémica distrajo durante largo tiempo la atención del tradicionista.

5 En La polémica Palma declara que se había propuesto escribir el artículo -junto con otros más- en el año 1877; como aparece fechado el 20 de octubre de 1877, no queda lugar a dudas sobre la fecha de su redacción. Esto obliga a pensar que 
polémico de cuantos escribió Palma. Por otra parte, es posible que la complejidad de los problemas que rodean las muertes de Monteagudo y Sánchez Carrión y la repercusión internacional del artículo de Palma haya conducido a algunos historiadores y literatos a abstenerse de participar en el debate suscitado. Por último, como el asunto es sumamente complejo nos hemos visto obligados a incorporar al texto un número de fechas aparentemente elevado.

El tono de la polémica desatada por el artículo de Palma fue muy violento y sin duda maltrató al tradicionista, quien no volvió a tocar temas relacionados con la historia contemporánea peruana. Años después, don Ricardo dejó testimonio de la forma en que este curioso asunto lo había afectado:

Yo bien sé (y por experiencia propia) lo peligroso que es tocar a los contemporáneos. Un trabajillo mío sobre Bolívar y Monteagudo (que habrá Ud. acaso leído al final de mi libro Tradiciones) provocó una polémica casi continental, polémica en que a mi modesta personalidad no le dejaron hueso sano. Llegó la exaltación hasta la indignidad de quemar sobre el proscenio de un teatro de Colombia un monigote de madera y trapo, bautizado con el nombre de Ricardo Palma. ${ }^{6}$

\section{Los hechos}

A las ocho de la noche del 28 de enero de 1825, mientras el coronel Bernardo de Monteagudo se dirigía a visitar a Juana Salguero, amiga suya, al llegar a la plaza de la Micheo (pequeña

era posible que Palma tuviera desde antes parte del material, lo que lo acerca a los hechos y a lo que pensaba el imaginario popular sobre los mismos.

6 Carta de Palma a Vicente Riva Palacio de 20 de noviembre de 1885. [En:] Ricardo Palma, Epistolario. (Lima, Editorial Universitaria de la Universidad Ricardo Palma, 2005.) Vol. 1º, pág. 287. 
plaza de Lima hoy desaparecida, de forma triangular, que hoy formaría parte de la calle Belén, cuadra 10 del jirón de la Unión), un desconocido lo atacó dándole muerte de una certera puñalada. Amparado por la oscuridad de la noche y la soledad de la calle el homicida huyó con facilidad. El asesinato se llevó a cabo sin testigo alguno y tan silenciosamente, que ni quienes se encontraban conversando en el interior de la botica en cuya puerta ocurrió sintieron ruido alguno. El asesinato no tuvo como móvil el robo puesto que el asesino no se apropió de las joyas que lucía ni del dinero que la víctima llevaba consigo.

Poco después, unos transeúntes hallaron el cadáver y dieron la alarma; los restos de Monteagudo fueron recogidos y llevados a la iglesia de San Juan de Dios (ubicada dentro de los linderos de la hoy Plaza San Martín). Dada la importancia que tenía Monteagudo, la noticia se esparció con rapidez y una hora después del crimen el propio libertador Bolívar estuvo, lleno de indignación, frente a sus restos.

Dos días después, el mulato Candelario Espinoza confesó ser el autor material del crimen pero sus declaraciones relacionadas con el autor intelectual fueron contradictorias. De inmediato, la opinión pública culpó tanto a alguna de las logias republicanas existentes por entonces en Lima cuanto a Faustino Sánchez Carrión, ${ }^{7}$ cabeza visible de la tendencia destinada a impedir el establecimiento en el Perú de un régimen vitalicio, llamárase este monarquía constitucional o presidencia vitalicia. No hay duda, pues, que Sánchez Carrión y Monteagudo eran claramente antagonistas.

7 Muchos deben haber tenido presente que dos años antes (diciembre de 1822), Sánchez Carrión había sido el gestor del decreto que establecía que la deportación de Monteagudo tenía el carácter de permanente y que en caso de que este retornara al Perú no se encontraría protegido por la ley. Era evidente que Monteagudo y Sánchez Carrión eran enemigos. 
Agotada la investigación policial y el procedimiento judicial correspondiente, Espinoza fue condenado a muerte; sin embargo, el 4 de marzo de 1826 Bolívar conmuta la pena impuesta y la reemplaza por diez años de cárcel en la prisión de San Lorenzo de Chagres (ubicada dentro de territorio de la entonces Gran Colombia de la cual Bolívar era presidente) y a su extrañamiento perpetuo del Perú.

Mientras tanto, José Faustino Sánchez Carrión era uno de los más importantes políticos del Perú republicano y el Congreso General Constituyente le había encargado (3 de abril de 1823) viajar a Guayaquil, junto con José Joaquín de Olmedo, para invitar a Bolívar a venir al Perú a fin de completar la guerra de la Independencia que se encontraba trabada. Cuando Bolívar llega al Perú (setiembre de 1823), sin duda tenía una relación estrecha con Sánchez Carrión y por eso no debe extrañar que lo designe para ocupar la Secretaría General de los Negocios de la República Peruana, una especie de ministerio único (abril de 1824); cuando este cargo desaparece en octubre del mismo año, Sánchez Carrión continúa desempeñándose como ministro de Gobierno y Relaciones Exteriores hasta que el 24 de febrero de 1825 , aduciendo un precario estado de salud, renuncia a toda actividad pública y se retira a convalecer a una hacienda ubicada en el valle de Lurín donde fallece el 2 de junio de 1825 . Su fallecimiento suscitó tal cantidad de sospechas que el gobierno dispuso que el profesor de la Universidad de San Marcos y futuro Protomédico general, Cayetano Heredia (1797-1857), practicara sobre los restos una autopsia que estableció que la muerte había ocurrido a raíz de un problema hepático.

\section{El año 1825}

Pese a que en diciembre de 1824 las fuerzas realistas habían sido derrotadas en la batalla de Ayacucho por el ejército 
patriota al mando de Sucre, con lo que quedaba asegurada la independencia peruana, 1825 fue en nuestro país un año sumamente complicado. Durante ese año, toda la autoridad gubernamental del Perú reposaba en el libertador Bolívar quien desde el 10 de setiembre de 1823, con el título de Libertador, gozaba del absoluto poder militar y, además, de la autoridad política directoral que lo facultaba a adoptar cualquier decisión relacionada con la guerra. La magnitud de su autoridad, rezaba el decreto expedido en esa fecha, "es tal cual lo exige la salvación del país. "Es decir, su autoridad carecía de limitaciones. Mientras tanto, el Marqués de Torre Tagle José Bernardo de Tagle, que hasta ese momento había ejercido la presidencia constitucional de la república, sospechando que Bolívar lo haría fusilar, se entrega al general español Juan Antonio Monet cuando los españoles ocupan nuevamente Lima a principios de febrero de 1824; sin embargo, no habiendo podido viajar a Chile, como pretendía, tuvo que refugiarse junto con las fuerzas realistas en los castillos del Callao donde fallece, con el resto de su familia, en noviembre de 1825 .

El Congreso Constituyente, que San Martín había dejado instalado en setiembre de 1822, aprobó el 12 de noviembre de 1823 la primera Constitución política del Perú, aunque la víspera“...había resuelto dejar en suspenso el cumplimiento de los artículos constitucionales que sean incompatibles con la autoridad y facultades que residen en el Libertador". En tal virtud, la Constitución, por decisión libre del propio Congreso Constituyente, en ningún momento tuvo plena vigencia. Más aún, el Congreso resolvió que el presidente Tagle “...se pondrá de acuerdo con el Libertador en todos los casos que sean de su atribución natural, y que no estén en oposición con las facultades otorgadas al Libertador," lo que significaba que el Presidente Constitucional de la República carecía de poder alguno pues todo debía consultarlo. Una vez consagrado este peligroso desorden administrativo, el 10 de 
marzo de 1825 el Congreso Constituyente declara que habían concluido sus funciones y decide disolverse para evitar que las atribuciones que le eran inherentes, pudieran enervar las que consciente y voluntariamente había concedido al Libertador.

La situación económica y financiera era igualmente confusa. Desde la llegada del Ejército Libertador a Paracas (setiembre de 1820), el comercio internacional había quedado prácticamente paralizado (lo que a mediano plazo resultaba insostenible porque las rentas de aduanas representaban un tercio de los ingresos fiscales) al igual de lo que ocurría con la agricultura y la magra industria nacional. Más aún, asentadas las fuerzas realistas en la sierra sur, tomaron posesión de la mayoría de yacimientos de oro y plata existentes en el antiguo virreinato lo que impidió que la autoridad independiente pudiera acuñar moneda, por lo que se vio en la necesidad de emitir papel moneda, medio de pago cuya aceptación implicaba generalmente un descuento. Por último, durante los cuatro años que había durado la campaña emancipadora los ejércitos de ambas partes recorrían el país obligando a los habitantes de pueblos y zonas rurales a subvencionarlos o a proporcionarles el avituallamiento necesario. Basadre describe bien la situación:

El orden y la seguridad que la agricultura, la minería y el comercio reclaman para florecer, faltaron a partir de 1820. El desgobierno, las campañas llevadas de uno a otro confín del territorio, los motines, las montoneras y los bandidos crearon condiciones adversas para el fomento material y social. ${ }^{8}$

Las consideraciones anteriores no entrañan crítica alguna sino, más bien, tratan de describir en forma breve las dificultades que tuvieron que enfrentar durante los primeros años de la

8 Jorge Basadre, Historia de la república del Perú. Tomo I, pág. 169. 
república quienes llegaron a sacrificar vida, familia y patrimonio luchando por la independencia peruana.

Pero el año al que estamos pasando revista fue importante, además, porque marca la desaparición de dos personajes que habían revestido especial importancia en aquellos años: en el primer semestre de 1825, con una separación de cuatro meses, se perpetró el asesinato de Bernardo de Monteagudo y ocurrió el fallecimiento de José Faustino Sánchez Carrión, cabezas visibles de los grupos que postulaban para el Perú regímenes políticos monárquico-constitucionales o republicanos, respectivamente. Y pronto se cumplirán doscientos años de ambas muertes sin que haya sido posible aclararlas en forma indubitable.

\section{La historia y los actores}

El artículo en que Palma historia los más importantes sucesos ocurridos en 1825 se titula Monteagudo y Sánchez Carrión y se refiere a hechos que habían tenido lugar ocho años antes de su nacimiento; es posible que el autor haya comenzado a interesarse en el asunto hacia mediados del siglo XIX, es decir, veinticinco años después de que estos hubieran ocurrido, y en momentos en que, por su importancia, el imaginario popular aún los tenía presentes. En su presentación, Palma enuncia el propósito de su trabajo con bastante claridad:

"Ya es tiempo de escudriñar la verdad histórica, apartando la venda que ciega a muchos, y de ofrecer a las generaciones que están por venir un estudio desapasionado. No conocimos a ninguno de los personajes políticos de aquella época, y por lo tanto no puede estraviarnos [sic]el afecto." 9

9 Ricardo Palma, Monteagudo y Sánchez Carrión. Estudio histórico. Pág. 


\subsection{Dos años de historia: 1820-1822}

La campaña de la Independencia del Perú se desarrolla en suelo peruano a partir del 8 de setiembre de 1820 en que la expedición libertadora que comandaba el general San Martín desembarca en Paracas. ${ }^{10} \mathrm{~A}$ partir de octubre, y mientras comienzan a aparecer en el Perú pronunciamientos favorables a la Independencia, San Martín embarca sus tropas hacia el norte de Lima y establece su cuartel general en Huaura. En ese mismo mes se lleva a cabo la Conferencia de Miraflores en que participaron representantes de San Martín y del virrey Joaquín de la Pezuela, sin llegar a acuerdo alguno.

En enero de 1821 tiene lugar el motín de Aznapuquio en que los jefes españoles destituyen a Pezuela y nombran en su lugar al general José de la Serna. El último esfuerzo por conciliar posiciones entre los libertadores y el régimen colonial fue la Conferencia de Punchauca (2 de junio) en que, sin éxito alguno, se entrevistan San Martín y la Serna. Tomando conciencia de lo precario de su situación, a principios de julio la autoridad española se retira de la capital desplazando al gobierno y sus tropas a la sierra sur cuya posesión mantendrá por tres años hasta la batalla de Ayacucho.

En esa situación, las fuerzas libertadoras ingresan sin dificultad a la capital (9 de julio), el Cabildo de Lima se declara favorable a la emancipación del antiguo virreinato(15 de julio) y el 28 de julio el general San Martín proclama la Independencia y se dedica a organizar el nuevo Estado. La primera disposición

189. Cito por la edición de Cachivaches (Lima, Imp. Torres Aguirre, 1900), la edición definitiva del trabajo.

10 Sin embargo, desde febrero de 1818 la escuadra libertadora al mando de Lord Cochrane había establecido el bloqueo del Callao, puerto al que bombardea en más de una ocasión. Al año siguiente llega a desembarcar en Pisco. 
de San Martín fue crear el Protectorado y asumir el mando con el título de Protector; de inmediato constituye un primer gabinete nombrando ministro de Gobierno y Relaciones Exteriores a Juan García del Río, de Guerra y Marina a Bernardo Monteagudo y de Hacienda a Hipólito Unanue. El 25 de octubre García del Río abandona el cargo y es reemplazado por Monteagudo que lo detentará hasta el 26 de julio de 1822. Durante casi un año, Monteagudo integra, pues, el Consejo de Ministros peruano.

Cuando San Martín viaja a Guayaquil para entrevistarse con Bolívar (20 de enero de 1822), encarga el mando del país con el título de Supremo Delegado a José Bernardo de Tagle (a quien el Congreso designaría Presidente Constitucional de la República a fines de año), quedando Monteagudo como ministro poderoso. En esos momentos, un importante grupo de limeños de todo nivel político y económico, temiendo que Monteagudo, en una nueva muestra de arbitrariedad, dispusiera la inmediata deportación de dos respetados liberales, Mariano Tramarria y Fernando Urquiaga ' $y$ de alrededor de otros cien patriotas más' suscribe una enérgica solicitud pidiendo la destitución del ministro. Ante el riesgo de ser destituido, Monteagudo presenta su renuncia que, sorpresivamente, es aceptada de inmediato; temiendo por su seguridad, el gobierno decreta su arresto domiciliario (26 de julio) pero, ante la imposibilidad de garantizar su integridad, las autoridades lo conducen al Callao (29 de julio) y lo embarcan furtivamente en la corbeta Limeña rumbo al norte (30 de julio) con la advertencia de que no podría desembarcar hasta Panamá.

El maltrato ejercido contra su canciller fue una de las razones por las cuales el Protector, a su vuelta a Lima a mediados de agosto, renuncia a su cargo, convoca al Congreso Constituyente y se aleja definitivamente del Perú. 


\subsection{Monteagudo}

El futuro ministro y canciller peruano coronel Bernardo de Monteagudo nació en Tucumán, norte del recién creado virreinato de La Plata, en 1789. Cursó estudios en la prestigiosa Universidad de Chuquisaca cuya Facultad de Jurisprudencia tenía por entonces mayor prestigio que la única universidad argentina con estudios de jurisprudencia, la de Córdoba; ${ }^{11} \mathrm{en}$ Chuquisaca alternó cuando menos con los próceres argentinos Cornelio Saavedra, Mariano Moreno y Juan José Castelli y el peruano Mariano Alejo Álvarez. Mientras Monteagudo se encontraba en Chuquisaca iniciándose en el ejercicio de la abogacía, tuvo lugar el levantamiento popular que depone a Ramón García de León y Pizarro, Presidente de la Audiencia de Charcas (1809): nuestro personaje fue uno de los líderes del levantamiento y, pese a que aún no había cumplido los veinte años, fue quien redactó la proclama revolucionaria. Pronto se le encuentra en la Provincias Unidas del Río de la Plata, al lado siempre de los grupos jacobinos, donde prepara un primer proyecto de constitución destinado a unir a las que habían sido colonias españolas en América del Sur y reorganizando la Sociedad Patriótica (1811-1813).

Después de pasar algunos años deportado en Europa, vuelve a América y desde 1817 aparece plegado a San Martín en su esfuerzo de completar la independencia de Sudamérica. Antes de viajar a Europa, Monteagudo había sido un extremista liberal; cuando vuelve, con una ideología totalmente morigerada, era un conservador radical. Se incorpora a las fuerzas que preparaba San Martín con el propósito de lograr la independencia de Chile y Perú con el importante cargo de

11 Enrique Finot, La cultura colonial española en el Alto Perú, pág. 18.(Nueva York, Instituto de las Españas en los Estados Unidos, 1935). 
Auditor de Guerra; establecido por un tiempo en Santiago de Chile, edita El Censor de la Revolución (1820), publicación eventual en la que da testimonio de que ya había abandonado su radicalismo inicial y se encontraba convertido, cada vez con mayor entusiasmo, en un fervoroso creyente del orden como recurso imprescindible de cualquier gobierno eficiente. Llega al Perú con el Ejército Libertador, desembarca en Paracas (setiembre de 1820) y hace toda la campaña libertadora al lado de San Martín como editor de los catorce números del Boletín del Ejército Unido Libertador del Perú.

Nombrado ministro de Guerra y Marina, primero, y de Gobierno y Relaciones Exteriores después, ejerce el poder con especial energía: gran parte de las medidas que adoptó fueron muy importantes, pero otras, en especial las adoptadas contra los españoles que aún permanecían en el antiguo virreinato, pusieron de manifiesto un innecesario radicalismo que le resultó contraproducente. Como consecuencia de sus actitudes y de la forma en que implementó algunas de sus disposiciones, Monteagudo unió en su contra a buena parte de los habitantes de Lima. Por eso, su deportación encontró a la población dividida entre quienes aprobaban o no la medida.

No hay duda de que Monteagudo fue un personaje sumamente inteligente y preparado cuyas ideas, como la siguiente, no podían simplemente desdeñarse pues encandilaron a quienes aún no habían adoptado con firmeza una posición clara sobre el régimen político que debía adoptar el antiguo virreinato de Nueva Castilla:

No pretendemos librar nuestra felicidad exclusivamente a una forma determinada de gobierno. Conocemos los males del despotismo y los peligros de la democracia. Ya hemos salido del período en que podíamos soportar el poder absoluto y, bien a costa 
nuestra, hemos aprendido a temer la tiranía del pueblo cuando llega a infatuarse con los delirios democráticos.

La primera parte de la vida en el Perú de don Bernardo de Monteagudo, contada desde su llegada a Paracas, no llega a los dos años.

Monteagudo pasa tres meses entre Guatemala y Panamá comenzando la preparación de sus memorias hasta que, pretendiendo volver al Perú, se dirige a Guayaquil (noviembre de 1822); al tomar conocimiento de sus andanzas y temiendo el resultado de las mismas, la Suprema Junta Gubernativa del Perú comisionada por el Soberano Congreso Constituyente, establece, a propuesta de Sánchez Carrión (decreto de 6 de diciembre de 1822) que Monteagudo quedaba “...perpetuamente extrañado del territorio de la República” y que “...queda fuera de la protección de ley en el momento de tocar cualquier punto del territorio de la República."

Pero es evidente que Monteagudo estaba interesado en reincorporarse al Perú: conocía virtudes y defectos del pueblo peruano y la ineficiencia que, a partir de su deportación, mostraba el gobierno favorecía su vuelta. Entre diciembre de 1822 y enero de 1823 lo tenemos entre Quito y Guayaquil, donde conoce a Bolívar; cuando el Libertador se establece en el Perú (setiembre de 1823) lo invita a incorporarse a su Estado Mayor y, así, a partir de julio de 1824 se inicia la segunda -e igualmente breve: 6 meses- etapa peruana de la vida de Monteagudo: después de integrar el Estado Mayor patriota en la batalla de Junín (6 de agosto) pasa a Lima a prestar servicios junto a Bolívar, y seguramente celebraron juntos el triunfo peruano en la batalla de Ayacucho (9 de diciembre).

Pero seis semanas después de que la noticia del triunfo en Ayacucho llegara a Lima, el 28 de enero de 1825 Monteagudo 
muere asesinado. Parecería que ya no gozaba de mayor predicamento gubernamental pues la Gaceta del Gobierno no da cuenta de su asesinato mientras que cuando cuatro meses después fallece Sánchez Carrión su necrología ocupa casi tres de sus cuatro páginas.

\subsection{Sánchez Carrión}

José Faustino Sánchez Carrión (1787-1825), nace en Huamachuco, sierra de Trujillo, pero pasa joven a Lima como alumno y precoz docente en el Convictorio de San Carlos y reputado profesor en la Universidad de San Marcos. Por razones que aún permanecen imprecisas (pudo haber sido extrañado de la capital o puede haber viajado a su ciudad natal a raíz de la muerte de su padre), entre fines de 1819 o principios de 1820 vuelve al norte del país y se le encuentra nuevamente en Trujillo y Huamachuco. Torna a Lima a fines de 1821, después de haber pasado buen tiempo en Sayán, localidad ubicada a $70 \mathrm{kms}$. al norte de la capital, reparando su ya por entonces deteriorada salud, y se vincula al semanario liberal Correo Mercantil, Político y Económico (cuyo primer número aparece el 19 de diciembre de 1821), en el que publica las famosas tres cartas suscritas como El Solitario de Sayán ( $1^{\circ}$ de marzo, 17 de agosto y 6 de setiembre de 1822) que luego se reprodujeron logrando mayor difusión en La Abeja Republicana (1822). En una de ellas sostenía “...la inadaptabilidad del gobierno monárquico al estado libre del Perú”.

La posición abiertamente favorable a los regímenes republicano y monárquico de Sánchez Carrión y Monteagudo, respectivamente, hizo que se convirtieran en rivales pues cada uno de ellos era la cabeza visible en el Perú de una de las tendencias. La deportación de Monteagudo y el triunfo de los 
postulados republicanos en el Congreso General Constituyente creado e instalado por San Martín, del cual Sánchez Carrión fue secretario (setiembre a noviembre de 1822), le facilitaron gestionar la aprobación de una ley mediante la que se establece que la deportación de Monteagudo tenía el carácter de permanente y que en caso de que este retornara al Perú, no se encontraría protegido por la ley (7 de diciembre de 1822).Es decir, no eran solo rivales sino claramente enemigos.

Mientras Monteagudo se encontraba en el exilio y residía en Quito, Sánchez Carrión recibió del Congreso (junio de 1823) el encargo de dirigirse a Guayaquil, junto con José Joaquín de Olmedo, para invitar a Bolívar a viajar al Perú y completar la campaña de la independencia que se encontraba entrampada. Ya en el Perú, Bolívar crea la Secretaría General de los Negocios de la República Peruana, una especie de ministerio único, que se la confía a Sánchez Carrión (3 de abril de 1824); mientras tanto, Monteagudo se reincorpora al Perú (julio de 1824). Reestructurado el sistema de gobierno, en octubre de 1824 Bolívar nombra ministro a Sánchez Carrión. Consolidada la Independencia con la batalla de Ayacucho, Bolívar confirma a este indoblegable republicano como Ministro de Gobierno y Relaciones Exteriores y lo designa vicepresidente del Consejo de Gobierno que habría de encargarse del Poder Ejecutivo mientras el Libertador viajaba al sur del país. ${ }^{12}$ Sin embargo,

12 Conviene aclarar esta serie de nombramientos: el 28 de octubre de 1824 , Bolívar nombra Ministro de Gobierno y Relaciones Exteriores a Sánchez Carrión, quien desempeña el cargo hasta fines de febrero del año siguiente; el 24 de febrero de 1825, Bolívar crea el Consejo de Gobierno (presidido por el general La Mar e integrado por Sánchez Carrión y Unanue) y le delega el mando político y militar del país mientras se encuentra de viaje a 'los departamentos del Sur'; el 1 de abril dispone que el Consejo se instale dos días después pero que el ministro de Guerra, general Tomás Heres, reemplace en el cargo a Sánchez Carrión quien “...se halla gravemente enfermo”. El Consejo de Gobierno, pues, no había podido reunirse puesto que su presidente, La Mar, se encontraba fuera del país (había retomado su vida privada en Cuenca, 
la salud de Sánchez Carrión estaba tan deteriorada que días después renuncia a ambos cargos y se retira al pueblo de Lurín donde fallece el 2 de junio de 1825.

\subsection{San Martín, Bolivar, Heres}

En el relato de Palma es necesario considerar a otras tres personas alrededor de las cuales giran estos incidentes: José de San Martín, Simón Bolívar y Tomás Heres.

José de San Martín llega al Perú en setiembre de 1820 al mando de un ejército compuesto en buena parte por argentinos y chilenos que había sido preparado en Mendoza (Argentina) durante varios meses. San Martín, después de contemplar la vida desordenada de las Provincias Unidas (Argentina) y Chile posterior a la Independencia, pensaba seriamente que el régimen político que convenía al Perú era la monarquía constitucional. Recién llegado al Perú, en la Conferencia de Miraflores (setiembre de 1820) ya había planteado en forma reservada “...la coronación de un príncipe de España en el Perú independizado"; ${ }^{13}$ en las negociaciones de Punchauca (mayo de 1821), propuso el establecimiento, en tanto no hubiera príncipe a quien encomendarle el nuevo país, de una regencia con un representante por cada parte y la presidencia del virrey; ${ }^{14}$ por último, despachó a Europa con similares propósitos a la misión conformada por Juan García del Río y Diego Paroissien (diciembre de 1821). No es necesario indicar que las gestiones de San Martín fueron infructuosas pero dan testimonio

Ecuador), y su vicepresidente, Sánchez Carrión, se encontraba visiblemente enfermo. Por eso, cinco semanas después Bolívar lo recompone y dispone que se instale el 3 de abril.

13 Basadre, La iniciación..., pág. 66.

14 Basadre, La iniciación..., pág. 67. 
de la marcada vocación del Libertador por una monarquía constitucional.

Simón Bolívar llega al Perú en setiembre de 1823, invitado por el Congreso General Constituyente Peruano. En realidad, el poder que el Congreso confiere a Bolívar es indiscutible dictadura pues un día antes de que entrara en vigencia la Constitución de 1823 el propio Congreso dispuso "...quedar en suspenso el cumplimiento de los artículos constitucionales que sean incompatibles con la autoridad y las facultades que residen en el Libertador [Bolívar] y con las que asisten al gobierno [es decir, al propio Congreso] para dictar las providencias más enérgicas y eficaces que son indispensables para la salvación del país. "En otras palabras, todo lo que no era compatible con las facultades concedidas al Libertador, carecía de vigencia. El 10 de febrero de 1825, el Congreso le renueva sus poderes y declara que “...el Libertador podrá suspender los artículos constitucionales, leyes y decretos que estén en oposición con la exigencia del bien público."

Bolívar, consciente de que necesitaba operadores políticos que colaboraran con él en el establecimiento de un régimen que lo mantuviera permanentemente en el poder, convoca a Monteagudo quien llega al Perú en julio de 1824 y, con la experiencia adquirida durante el año en que fue ministro de San Martín, comienza a promover exitosamente un régimen absolutista que favoreciera al Libertador: en esta actividad, a la cual se aboca entre agosto de 1824 y enero de 1825 , se enfrenta abiertamente con Sánchez Carrión quien, como se ha indicado, no era su rival sino su enemigo. Después de recorrer el sur del país y de ponderar la situación, Bolívar repara en que su gobierno es suficientemente fuerte y opta por iniciar la preparación de un mecanismo de gobierno que le iba a permitir ejercer como monarca aunque sin emplear el título: una Constitución vitalicia tal como la que ya existía en Bolivia. 
Tomás de Heres (1785-1842) fue un militar venezolano que llega al Perú en 1819.En la batalla de Junín de desempeña como jefe del Estado Mayor General de Bolívar y, como tal, firma el parte oficial de la batalla. Bolívar nombra a Heres ministro de Guerra (octubre de 1824), de Gobierno y Relaciones Exteriores (abril a junio de 1825) y de Guerra y Marina (setiembre a diciembre de 1825). En 1825, en momentos en que ocurre el asesinato de Monteagudo, se desempeñaba como ministro de Guerra: dos meses después fue incorporado al Consejo de Gobierno. En 1827,vuelve a Venezuela, donde muere asesinado en 1842).

\section{El asesinato de Monteagudo}

Antes de las ocho de la noche del 28 de enero de 1825, Monteagudo se dirigía en Lima a pie hacia la calle de Belén (hoy cuadra 10 del jirón de la Unión) a visitar a una amiga, doña Juana Salguero. Cuando caminaba entre la Plaza de San Juan de Dios (hoy Plaza San Martín) y la Plaza de la Micheo (pequeña plaza triangular contigua, hoy desaparecida), apareció una persona (las investigaciones determinaron que se trataba de dos delincuentes pero que solo uno llegó a atacarlo) que le clavó un puñal a la altura del corazón y que dejó el puñal incrustado en el cuerpo de la víctima. El asesinato se llevó a cabo en una noche oscura, en momentos en que no había nadie cerca del lugar del crimen y en forma silenciosa pues nada oyeron quienes se encontraban conversando en la farmacia ubicada en la misma acera, por lo que el asesino pudo retirarse sin dificultad. El agresor no se apropió de bien alguno de su víctima -que portaba varias joyas de valor y dinero en efectivo-, lo que permitió confirmar que el móvil del asesinato no había sido el robo.

Unos transeúntes que hallaron el cadáver lo llevaron a la iglesia de San Juan de Dios. Una vez identificado el cadáver, la noticia 
del asesinato del antiguo y controvertido ministro se difundió por toda la ciudad. El propio Bolívar llegó a la iglesia a las nueve de la noche y, refiere Palma, “...es fama que contemplando el cadáver, esclamó [sic] muy conmovido - Monteagudo! Monteagudo! Serás vengado."

\section{I La investigación, el proceso judicial y la opinión pública}

Entre todos los problemas que el Perú enfrentaba en esos momentos, el asesinato de Monteagudo fue uno de los que atrajo más la atención debido a los antecedentes sociales y políticos de la víctima. Para estudiar su esclarecimiento es necesario considerar las investigaciones realizadas, el proceso judicial llevado a cabo y la opinión pública.

\subsection{La investigación}

Las investigaciones para determinar quién había acabado con la vida de Monteagudo se iniciaron de inmediato y estuvieron centradas alrededor del único medio probatorio con que se contaba: el puñal asesino. Como se trataba de un arma nueva que parecía haber sido afilada recientemente, la policía reunió a los 43 barberos que había en Lima, uno de los cuales informó que "...el día 26 fue a su tienda, situada en la calle de Plateros de San Agustín, un negro, como de 20 años de edad, y le pagó un real porque afilase dicha arma; que ignoraba su nombre, pero que si le veía podría señalarlo." ${ }^{15}$ Convocados de inmediato todos los hombres de color residentes en Lima para que se presentaran al patio del Palacio presidencial, el barbero reconoció como el dueño del puñal a “...Candelario Espinoza, negrito claro, de diez y nueve años

15 Las citas textuales, en cursiva, corresponden al artículo de Palma. 
de edad, y que había sido soldado de caballería en el ejército patriota. A esa edad, contaba ya con otro asesinato y varios robos. "Algunos historiadores le atribuyen haber sido torero y haber cometido anteriormente dos asesinatos.

También se detuvo a Ramón Moreira, “...limeño como Espinoza, esclavo, zambo y de veintidós años”, quien declaró que “...Espinoza lo había comprometido para practicar un robo en la calle Trinidad; que encontraron por San Juan de Dios a un caballero muy bien vestido, y que su compañero le dijo: "ese tiene reloj, vamos a quitárselo", y que Espinoza se abalanzó sobre el transeúnte, cuchillo en mano; que emprendieron la fuga, y por el camino le dijo: -- "hasta el cuchillo se lo he dejado adentro, vaya por las que ha hecho”. Ante la policía, Espinoza declaró haber matado a un caballero pero ignorando que se trataba de Monteagudo. Las autoridades no pudieron obtener información adicional pese a que sometieron a Espinoza a tortura.

\subsubsection{El proceso judicial.}

El proceso judicial se inició de inmediato y avanzó con rapidez puesto que poco era lo quedaba por dilucidar. Sin embargo, el 26 de marzo del mismo año ocurre algo singular: el ministro Hipólito Unanue dispone que el asunto pase a ser visto por un tribunal ad-hoc integrado por Fernando López Aldana, José Larrea y Loredo y Francisco Valdivieso como vocales, y José María Galdeano y Manuel Tellería como auditores. ${ }^{16}$ Se

16 El Tribunal ad-hoc que nombra Unanue estaba integrado por personas intachables: López Aldana, Valdivieso y Larrea habían sido nombrados vocales de la Corte Suprema por Bolívar seis semanas antes (8 de febrero); Larrea era amigo de Bolívar y, además, integró el Consejo de Gobierno que colaboró con el Libertador; Galdeano y Tellería, en su condición de auditores, dependían del Ejecutivo. Por su composición, se podía advertir la fuerte influencia que Bolívar podía ejercer sobre la sala. 
excusó de participar en este tribunal Mariano Alejo Álvarez quien, como López Aldana y Valdivieso, también había sido nombrado vocal de la Corte Suprema en enero de 1825. ${ }^{17}$ Todos los designados gozaban de excelente reputación pero tenían, como antecedente, haberse opuesto en algún momento a Monteagudo.

Todos los tribunales por los que pasó este proceso, escribe Palma, estuvieron uniformes en condenar a Espinoza a la pena de muerte, y a su cómplice Ramón Moreira a la de diez años de presidio, absolviendo a los [otros] tres señores acusados.

Bolívar, que por entonces se encontraba de viaje por el sur del país y Bolivia, seguía el procedimiento muy de cerca y había dispuesto que cada vez que el tribunal adoptara una decisión, se le informara de inmediato. ${ }^{18}$

Cuando el último tribunal expidió sentencia sin variar la decisión de aplicar la pena de muerte a Espinoza, el 4 de marzo de 1826 Bolívar expide el siguiente decreto:

"Usando de las facultades extraordinarias de que me hallo investido, vengo en conmutar la pena ordinaria a que ha sido condenado Candelario Espinoza, en diez años de presidio al [sic] de Chagres $^{19}$ y extrañamiento perpetuo de la República:

17 Refiere Palma que Mariano Alejo Álvarez “...fundó su excusa en que para cumplir bien con el cargo tenía que empezar por poner en la cárcel a un Ministro de Estado. Aludía a Sánchez Carrión." (Palma, Monteagudo..., pág. 205.)

18 Palma ofrece testimonios de lo dicho transcribiendo oficios enviados por Bolívar y suscritos por Felipe Santiago Estenós, quien actuó como secretario del Libertador antes de la partida del viaje al sur, el 1 de abril de 1825. Dice Palma que “...cada vez que un Tribunal fallaba, se daba aviso a Bolivar, ausente a la sazón en el Sur. En nota de 4 de setiembre, fechada en La Paz y suscrita por su secretario Estenós, y en otro oficio de Oruro, del 25 del mismo mes, hacía hincapié el Libertador en que no debía quedar sin efecto su promesa de perdonar la vida al reo."

19 El castillo de Chagres, ubicado en Panamá, había sido construido en el siglo xvi; sufrió los embates de corsarios y piratas hasta que a principios del siglo 
a Ramón Moreira en seis años de presidio en el mismo sitio: y en lo demás, que se lleve a efecto lo contenido en dicha sentencia." 20

Al transcribir el decreto anterior, Palma observa que en toda la vida pública del Libertador en el Perú este fue el único decreto en que Bolívar hizo empleo del poder dictatorial del cual estaba investido.

\subsubsection{La opinión pública}

Según avanzaba el procedimiento judicial contra Espinoza, la opinión pública iba teniendo una idea cada vez más clara de quién había sido el autor material del asesinato de Monteagudo, para lo cual no necesitaba ser especialmente zahorí pues Espinoza ya lo había reconocido. Sin embargo, la ciudadanía no lograba resolver dos asuntos de especial interés: ¿̇cuál había sido el móvil del crimen? y ¿quién o quiénes podrían haberlo promovido, es decir, quiénes podían haber sido los autores intelectuales?

Sobre el móvil del crimen se plantearon diversas alternativas: (l) buena parte de la población limeña culpó del crimen a la Logia republicana cuyo entusiasmo había decaído después de los primeros éxitos del sector liberal pero que, temerosa de que Monteagudo pudiera tratar de impulsar nuevamente el régimen monárquico, se había recompuesto. Refiriéndose a lo que había ocurrido entre 1821 y 1822, Palma manifiesta que, temiendo enfrentarse nuevamente a Monteagudo, “...los republicanos sinceros

xix fue convertido en prisión. Puesto que en esa época Panamá formaba parte de Colombia, Bolívar, en su condición de presidente de la Gran Colombia, no tuvo dificultad en enviar a un detenido a que cumpliera allí su condena.

20 Palma, Monteagudo..., pp.206. 
entraron en alarma y temieron con razón, que mientras Monteagudo tuviese injerencia en la cosa pública la causa de la República estaría en peligro. Monteagudo minaba el terreno, con lentitud, es cierto, pero de una manera segura, y contaba con un número creciente de correlijionarios[sic]. Esta propaganda, ejercida por un hombre de su talento y energía, asustó a los demócratas que para combatirla organizaron una Lojia...". Vuelto Monteagudo al Perú, la Logia debió haber cobrado nuevos ánimos; (2) otra parte de la población señalaba como responsable, de entre la Logia, a Sánchez Carrión. A favor de esa atribución corrían dos hechos: las palabras del más enérgico de los vocales supremos, Mariano Alejo Álvarez, quien, como se ha visto, se había negado a integrar el tribunal especial nombrado por Unanue el 26 de marzo de 1825 arguyendo que tendría que pedir el encarcelamiento de un ministro el cual, según Palma, no podía ser otro que Sánchez Carrión ${ }^{21}$ y que había sido precisamente Sánchez Carrión quien había gestionado exitosamente que el destierro de Monteagudo tuviera el carácter de permanente; (3) otro grupo señalaba como culpables a los españoles que habían sido expulsados del país despojados de sus bienes en tiempos en que Monteagudo era ministro de Gobierno y Relaciones Exteriores. El día de la Independencia había en el Perú 10.000 españoles y criollos, todos adinerados, quienes movían agricultura, comercio e industria en el virreinato;un año después, solo quedaban 700 pero pobres y agobiados por las persecuciones. En otras circunstancias hubieran podido haber sido los responsables, pero en ese momento ya no: cuando el gobierno peruano se allanó a devolverles algunas propiedades, solo dos volvieron al Perú; (4) algunos, por último, culpaban a algún marido ultrajado pues dentro de la sociedad limeña Monteagudo tenía un bien ganado prestigio de agradable hombre de mundo, sibarita y de vida galante. ${ }^{22}$

21 Vid. supra, nota $\mathrm{N}^{\circ} 17$,

22 En la tradición titulada María Abascal, Palma cuenta que era probable que 
Mucho menor fuerza podía tener cualquier testimonio verosímil de Candelario Espinoza, puesto que no solo no formaba parte del expediente sino porque Bolívar, el único que podía haberlo hecho público si es que el testimonio existió, nunca lo había difundido. Es decir, aparentemente los únicos dos que sabían con certeza quiénes habían sido los autores intelectuales del crimen eran Bolívar y Candelario Espinoza, y aparentemente ambos se llevaron el secreto a la tumba.

En el Perú Monteagudo había sido una autoridad respetada pero, en especial temida, había hacia él una marcada actitud de rechazo que derivaba de la energía(que podría tener un componente de abuso) con que actuó durante el año en que se desempeñó como Ministro de Estado. Algunos historiadores lo censuran claramente: un hombre ponderado como Santiago Távara (1790-1874), testigo directo de las decisiones de Monteagudo, describía en 1862 la imagen que del ministro tenían los habitantes del recién independizado país: "Monteagudo [...] había befado a todos los partidos, insultado a todas las clases, [...] no tenía ni hogar ni afección en el país"; ${ }^{23}$ Nemesio Vargas, en 1903, pese a que reconocía la buena formación y las especiales dotes que tenía, admite que “...se había hecho odiar. Falto del temor a Dios, carecía de humanidad;" "Vargas Ugarte resume la situación: "Las medidas adoptadas por Monteagudo contra los españoles no solo hirieron a éstos sino que provocaron las protestas de muchos americanos relacionados con ellos. [...] No podían salir de sus casas después del toque de oraciones, se les prohibía el uso de armas y en caso de ausentarse

la bella joven limeña de ese nombre había mantenido alguna relación con Monteagudo entre 1821 y 1822 y que el día del asesinato ingresó corriendo al templo de San Juan de Dios a llorar frente a su cadáver. En la tradición, Palma cuenta que la conoció hacia 1845 y que murió, de 92 años de edad, en 1898.

23 Santiago Távara, Historia de los partidos. Pág. 10. (Lima, Editorial Huascarán, 1951).

24 Nemesio Vargas, Historia del Perú independiente, tomo iii, pág.52. 
a la Península o al territorio ocupado por el enemigo, perdían todos o la mayoría de sus bienes"; ${ }^{25}$ por último, Basadre reconoce que “...parte de la nobleza limeña y los españoles peruanos que habían sido víctimas de aquel mulato tempestuoso, se alejaron de él y lo echaron abajo, pero perdiendo con ello un defensor valioso..." 26 Es necesario observar que los cuatro testimonios aluden a españoles y criollos que se vieron perjudicados económicamente. Sin embargo, entre los juicios emitidos sobre aquellos complejos años aparecen justificaciones y reconocimientos de historiadores igualmente reputados, como Paz Soldán:

San Martín y Monteagudo, esas dos colosales figuras, que serán más grandes mientras más se les examine, comprendieron muy bien que debían cerrar los ojos a la compasión y a la debilidad. Era preciso confiscar los bienes a los enemigos, perseguirlos, desterrarlos, quitarles todo recurso e imponerles terror: dolorosa era la situación pero imprescindible; u obraban así o se perdía la santa causa que abrazaron; por esto se decretó que pues que los españoles que juraran la independencia y permanecieran tranquilos respetando al nuevo Gobierno y leyes, serían amparados en su persona y bienes; pero los que permanecieran trabajando contra el orden nuevamente establecido, experimentarían todo el rigor de la ley y perderían sus propiedades. ${ }^{27}$

Pero nadie podía desconocer la importante obra que Monteagudo había llevado a cabo durante los casi doce meses en que se encontró en el gobierno, tanto conjuntamente con San Martín cuanto valiéndose de las enormes facultades que el Protector había delegado en sus ministros: se establece que

25 Rubén Vargas Ugarte S.J., Historia del Perú. Emancipación. (1809-1925). (Buenos Aires, 1958). Pág. 327.

26 Basadre, La iniciación..., pág. 74.

27 Mariano Felipe Paz Soldán, Historia del Perú Independiente. Vol. 1, pág.243. (Lima, 1868). 
todos los hijos de esclavos nacidos a partir de la Independencia, nacían libres; ${ }^{28}$ se dispone que los esclavos que servían en el ejército quedaban libres si demostraban valor en el combate y que los esclavos de propiedad de extranjeros quedaban libres en momentos de pisar el territorio nacional, se condena la pena del azote y se establece quien la aplique a una persona libre será considerado como enemigo de la patria y castigado severamente, se ordena la demolición de los calabozos subterráneos destinados a dar tormento a los detenidos, se declara la libertad de imprenta, se establece la franquicia postal para los periódicos, etc. Leguía y Martínez recuerda otras decisiones importantes de Monteagudo: la abolición del tributo y de la mita, las disposiciones de carácter educativo como la obligación de impartir educación en los conventos y la reapertura del Convictorio Carolino y el Seminario de Santo Toribio, las decisiones de carácter cultural tales como la creación del museo nacional y la prohibición de comercializar material arqueológico, la creación del Censor del teatro, las prohibiciones destinadas a suprimir costumbres tradicionales como el juego de azar y el juego con agua durante los carnavales, la limitación de los toques de campana $\mathrm{y}$, por último, la realización de innumerables obras públicas de importancia como creación de cárceles, mejoramiento del servicio de agua, la construcción de la Plazuela del Teatro y el Mercado Central. Leguía y Martínez califica la obra de Monteagudo como fantástica. Durante su año como ministro, la presencia del estadista tucumano no pudo haber pasado desapercibida.

28 Paz Soldán comenta la decisión adoptada: "En este decreto se ve la grandeza de las ideas de San Martín y de su Ministro Monteagudo: sabían que los dueños de esclavos, cuyo número pasaba de 40.000, eran atacados en sus derechos de propiedad, mal adquirida en su origen y de dudoso derecho, desde que se contraría la ley natural; pero entre salvar un principio o exponerse al enojo y oposición de una parte de la sociedad, no se dudó. "(Paz Soldán, Historia del Perú... Vol. 1, pág.236. 
Pero si tiene en cuenta lo positivo y lo negativo de la obra de Monteagudo el fiel de la balanza se inclina hacia lo segundo si se considera la creación de un sistema de espionaje que fue conocido como la "compañía disfrazada", que tuvo como propósito no perder paso de las actividades de los españoles que habían quedado en el Perú, de los criollos que optaron por no emigrar y, por supuesto, de la Iglesia que aún mantenía su poder.

\subsection{Aportes adicionales proporcionados por Palma}

El parágrafo anterior es la relación cronológica de las investigaciones y el proceso judicial llevados a cabo para identificar y sancionar al asesino de Monteagudo. Sin embargo, en su indagación histórica Palma encuentra material adicional de interés.

\subsubsection{La información del coronel Espinar}

El coronel José Domingo Espinar (1791-1869) fue un militar gran colombiano que llega al Perú con Bolívar. En 1825, Espinar ya no era secretario del Libertador pero sí uno de los hombres de más confianza que tenía en el Perú. Palma refiere que Bolívar, al enterarse de que la autoridad no había podido obtener una confesión completa de Espinoza, urde un nuevo mecanismo:

Bolívar comisionó entonces (30 de enero) al coronel Espinar, su secretario en otra época, y éste, más sagaz o afortunado, consiguió que Espinoza conviniera en revelar su secreto, pero al Libertador en persona.

Y Palma continúa su relato:

No consta del proceso; pero el coronel Espinar refirió en 1856 
al que esto escribe [es decir, al propio Palma] que, a las once del 31 [de enero], fue Candelario llevado con esposas y grillos. Lo subieron cargado en hombros de los soldados. El Libertador se hallaba acompañado de los señores Unanue, Pando y general don Tomás Heres. Mandó que dieran a Espinoza una copa de vino, pues desde la hora de su prisión no había tomado alimento. [...] Bolívar se encerró con el reo y después de empeñarle palabra de que le salvaría la vida, hízole el criminal revelaciones que serán siempre un secreto para la Historia; pero que debieron ser de gran importancia si se atiende a que, más tarde, para cumplir su palabra, tuvo el Libertador que hacer uso de las facultades discrecionales que le acordaba la dictadura $[\ldots]^{29}$

\subsubsection{El folleto de Mosquera}

Uno de los más curiosos documentos a los que alude Palma en el Prólogo a sus Cachivaches es el folleto de 18 páginas Bolívar y sus detractores, escrito por el general Tomás Cipriano de Mosquera, fechado en Popayán el 20 de setiembre de $1878 .{ }^{30}$ Mosquera, pocas semanas antes de morir, enuncia los títulos con los cuales declara: "Pocos individuos pueden decir lo que yo que, como ayudante de campo, secretario privado, secretario general, y el último jefe de Estado Mayor de Bolívar, soy depositario de muchísimos de sus secretos." Amparado por el énfasis de la declaración anterior, todo lo cual es cierto, Mosquera procede a describir diferentes hechos relacionados con los sucesos

29 El texto transcrito corresponde a las páginas 204 y 205 del artículo de Palma.

30 Sobre Mosquera debe formularse una advertencia. El general Mosquera fue embajador de la Gran Colombia en el Perú entre 1828 y 1830 y aparentemente es el responsable de la invención del inexistente Tratado Pedemonte-Mosquera que durante casi un siglo fue aducido por Ecuador en defensa de sus derechos amazónicos. Por lo tanto, lo manifestado por él no puede tomarse sin especial cuidado. 
descritos en el artículo de Palma confirmando, en primer lugar, la realización de la entrevista privada sostenida por Bolívar y Candelario Espinoza tal cual-según manifiesta-se la refirió el Libertador:

El presunto reo negaba todo, y le ocurrió al Libertador interrogarlo él mismo, y lo hizo llevar a una sala de Palacio, que estaba alumbrada con una sola bujía. Interrogando al asesino, exclamó repentinamente Bolívar: -Mira, en el fondo de este salón, al alma de Monteagudo que te acusa de ser su asesino.-El negro se conmovió y dijo: -yo confieso todo, pero no me maten.-Aquí le respondió el Libertador:-descúbreme todo, y te perdono.-Dobló las rodillas el asesino, y dijo estas tremendas palabras: -El señor Sánchez Carrión me dio cincuenta doblones de a cuatro pesos, en oro, para que matara a Monteagudo, por enemigo de los negros y de los peruanos.

El Libertador me decía al contarme esta escena: -se me heló la sangre al oír el nombre de un amigo a quien yo apreciaba tanto: no quise que entonces se descubriera este secreto, y solamente se lo conté al General.***

El General *** a quien hizo Bolívar esta confianza era íntimo amigo de Monteagudo, y veía con celo la amistad de Sánchez Carrión con Bolívar, y determinó vengar a Monteagudo, y sacar del medio al hombre por quien tenía Bolívar tanto afecto y que creía que le menguaba su influencia. ${ }^{31}$

Aquí termina la parte del artículo de Palma relacionada con el asesinato de Monteagudo. De sus veinte páginas, el asunto del asesinato de Monteagudo cubre casi diecisiete. Palma concluye, pues, así diera por ciertas las declaraciones de Espinar y Mosquera, sin responsabilizar a nadie por el asesinato de Monteagudo. Pero es necesario determinar cuánto

31 Palma, Cachivaches, pág. 233. 
de lo referido por el tradicionista puede admitirse: lo que se refiere al asesinato proviene del expediente y es, por lo tanto, indiscutible; sobre los motivos del asesinato es posible descartar el robo, puesto que el asesino no tocó las joyas y dinero que el ex ministro llevaba consigo; admitido que el asesino fue Espinoza, pues él mismo lo confesó, quedan dos posibilidades: la primera, que el crimen hubiera sido político, tal como lo sostiene Palma; la segunda, que no se puede descartar, absolutamente, que el crimen hubiera derivado de causas menores como venganza de españoles o criollos migrados o de la vida galante que llevaba el ex ministro (asunto que nadie ha estudiado). En caso de haber sido político el móvil, hasta hoy no aparece el eslabón que ligue a Sánchez Carrión con el delito. Y, a dos siglos de distancia, contribuye a mantener la duda el que el gran apoyo que recibe la tesis de Palma sea el testimonio de Mosquera, que si bien llegó a ocupar cuatro veces la presidencia de Colombia, en el Perú su palabra no puede aceptarse plenamente dada su vinculación con el falso Protocolo Pedemonte-Mosquera presuntamente suscrito en 1830.

\section{La participación de Sánchez Carrión}

La figura de José Faustino Sánchez Carrión contrasta con la de Monteagudo. Nacido en Huamachuco proveniente de una típica familia serrana católica practicante, fue preparado desde niño para ejercer el sacerdocio y sus primeras actividades estuvieron vinculadas con estudios y docencia tanto en Trujillo como en Lima. Fue un trabajador incansable y se registra su paso por una multitud de ciudades de la sierra norte del Perú. Pese a sus limitados ingresos como maestro en el Convictorio de San Carlos, casó hacia 1819 y tuvo cuatro hijos que seguramente fueron educados dentro de un régimen austero. 
Es posible que Sánchez Carrión nunca gozara de salud perfecta; más aún, de sus seis hermanos solo uno sobrevivió a la infancia. Hay dos momentos en su vida que abonan la impresión de que tenía problemas de salud: en 1820 retorna a su Huamachuco natal sin que se pueda asegurar si fue a raíz de la muerte de su padre o por razones de descanso o restablecimiento; poco tiempo después se le encuentra durante un largo período, por razones que se ignoran, en Sayán, bucólica serranía ubicada a $70 \mathrm{kms}$. al norte de Lima. Es lugar común entre sus biógrafos referirse a su mala salud, pero ninguno ha precisado de qué padecía ni el tratamiento que recibía, si es que tuvo alguno.

Sánchez Carrión no había pasado desapercibido como estudiante ni como docente. Es posible que su juvenil vida política se hubiera iniciado a mediados de la década de 1810 , pues en tiempos de Abascal la autoridad ya lo había tenido bajo observación; en 1819 el virrey Pezuela había dispuesto que saliera de Lima pues dijo que, con su oratoria, tenía a la ciudad revuelta. Sin embargo, la vida pública de Sánchez Carrión se inicia cuando después de estar en Trujillo y Huamachuco vuelve a Lima a fines de 1821, en momentos en que los esfuerzos del gobierno Protector por impulsar la monarquía constitucional eran cada vez más evidentes: en términos generales se respetaban los títulos nobiliarios españoles, se creaba la Orden del Sol como émulo para la futura nobleza local, se creaba la Sociedad Patriótica (10 de enero de 1822) y San Martín viajaba a Guayaquil en busca de Bolívar quedando Monteagudo como ministro excepcionalmente poderoso. Mientras tanto, la participación de Sánchez Carrión en el trajín político de aquellos desordenados meses no se dio en la Sociedad Patriótica, a la cual no pertenecía, sino por intermedio de las tres cartas que, en defensa del régimen republicano, publicó en el bisemanario limeño Correo Mercantil, Político y Literario (1822) y que después fueran reproducidas en La Abeja Republicana y que suscribe con el 
seudónimo de El Solitario de Sayán. Durante el primer semestre de 1822, en ausencia de San Martín y encontrándose el país al mando del débil Tagle, los enfrentamientos soterrados -puesto que no eran públicos- entre Sánchez Carrión y Monteagudo tienen que haber sido sumamente fuertes y llegan a su término recién el 26 de julio cuando este último se ve obligado a renunciar al cargo que detentaba y abandonar el país.

Hacia comienzos de 1822, para el pueblo limeño, había sido fácil apreciar las medidas visibles que desde hace algunos meses venía implementando Monteagudo en su esfuerzo por conseguir adeptos al régimen que San Martín y él venían promoviendo; mientras tanto, Sánchez Carrión no tenía obra material que lucir. El estudioso huamachucano se limitaba a difundir con el grupo liberal su ideología republicana pues recién cuando en setiembre de 1822 se incorpora al Congreso Constituyente y es elegido su primer secretario pasa a ser, primus inter pares, el líder de su posición: fue uno de los congresistas que más aportó para la redacción de la Constitución liberal de 1823 y la claridad de su visión sobre la cada vez peor situación por la que atravesaba el Perú y su capacidad para expresarla fueron decisivas para que se invitara a Bolívar a venir al Perú a completar la guerra de la Independencia.

Si avanzamos hasta 1825 podremos reparar que tanto Monteagudo cuanto Sánchez Carrión gozaban, por distintas razones, del favor de Bolívar a quien habían conocido casi simultáneamente en el primer semestre de 1823: al primero, a quien había conocido entre Quito y Guayaquil, debido a la clara visión que tenía del proyecto multinacional bolivariano y porque debía haber quedado impresionado por su capacidad de maniobra política; al segundo, a quien conoce en Guayaquil cuando, en nombre y representación del gobierno, lo invita a aceptar lo que en el Perú llegó a entenderse como dictadura. 


\section{El fallecimiento de Sánchez Carrión}

Desde su vuelta al Perú, Monteagudo no había detentado cargo público alguno pero su cercanía a Bolívar era evidente: forma parte del Estado Mayor que acompaña al Libertador en la batalla de Junín (6 de agosto) y a fines de diciembre recibe junto con él la noticia del triunfo de Ayacucho y continúa con su exitosa labor promotora de un gobierno vitalicio. En su artículo histórico, Palma intenta describir, aunque ya en forma parcializada, la situación:

Entretanto, la obra de Monteagudo adquiría gran consistencia y su triunfo parecía inevitable. Bolívar era una voluntad resuelta; pero necesitaba de otra inteligencia que se encargara de los detalles o pormenores del plan... [...] La Logia resolvió atropellar por todo para salvar a la República.

Con la desaparición de Monteagudo a fines de enero, se debilita en forma sustancial la posición favorable a la monarquía constitucional o régimen similar en el Perú, y muy fortalecido el régimen republicano. Pero ese es el momento en que ocurre lo inesperado: hacia mediados de febrero, la cabeza del grupo republicano, Sánchez Carrión, quien se desempeñaba como ministro desde marzo del año anterior, comienza a sentir que su salud se deteriora de manera tal que el día 25 formula renuncia al cargo por hallarse, al decir de Palma, “...gravemente enfermo $e$ imposibilitado para atender al despacho del Ministerio”. El gobierno acepta su renuncia solo en términos formales ya que el 9 de abril Bolívar recompone el Consejo de Gobierno que habría de ejercer las funciones ejecutivas en Lima mientras el Libertador viajaba al Cuzco, y designa para integrarlo “...a D.D. José María de Pando, hasta que restablecido el Dr. Sánchez Carrión vuelva a encargarse del despacho de su Ministerio, "lo que indica que Bolívar continuaba confiando en él. Trasladado Sánchez Carrión a 
Lurín para convalecer en la hacienda de los sacerdotes de la congregación de San Felipe Neri, fallece repentinamente en la tarde del 2 de junio de 1825. Heres informa de lo ocurrido a Bolívar, quien acababa de hacer su ingreso triunfal al Cuzco:

Sánchez Carrión, después de hallarse aparentemente bueno y en estado de venirse de un día a otro a desempeñar su destino, ha muerto repentinamente en Lurín, el 2 del corriente por la tarde. Había estado aquel mismo día a caballo y con muy buen humor; concluido su paseo, se puso en cama a reposar y habiendo en estas circunstancias entrando su cuñada a verlo, lo encontró expirando. Inquieto yo con esta muerte, y con muchos deseos de saber la causa del mal, que había podido ocultarse hasta el grado de engañar a los facultativos y aún al mismo paciente, convine con el señor Unanue en mandar un cirujano que abriese el cadáver y lo observase. Fue efectivamente y del reconocimiento ha resultado que tenía en el hígado un aneurisma reventado; y de aquí se ha creído que sus paseos a caballo fueron dilatando los vasos hasta reventarlos. Así, Sánchez Carrión se dio la muerte por los mismos medios que buscaba su salud. ${ }^{32}$

En opinión del autor de estar líneas, Palma incurre en su artículo en dos fallas: una, relacionada con la salud de Sánchez Carrión; otra, concediéndole mérito probatorio al folleto de Mosquera. Al referirse, como lo hace, a la “...vigorosa salud de Sánchez-Carrión” (pág.207) Palma pierde objetividad pues todos los testimonios existentes sobre el ilustre congresista de 1822 inducen a sospechar que a lo largo de toda su relativamente corta vida nunca gozó de salud perfecta. E indicar, cincuenta años después y basándose aparentemente en la tradición oral, que la salud de Sánchez Carrión empezó a decaer “...desde el día

32 Jorge Basadre, Peruanos del siglo xix. Pág.188. (Lima, Ediciones Rikchay Perú, 1981). 
del siniestro desayuno" al cual lo invitó Bolívar es una afirmación que hubiera sido imprescindible apoyar en una prueba sólida pues ampararse veinticinco años después en el imaginario popular es prueba que no resiste el menor análisis.

Por otra parte, es posible que el tres veces presidente de Colombia general Tomás Cipriano de Mosquera haya sido un digno patriota colombiano, un ejemplar mandatario de su país y un buen encargado de negocios de Colombia en el Perú. Sin embargo, la participación que le cupo en la confección del falso Protocolo Pedemonte-Mosquera descalifica absolutamente su opinión. En la década de 1870, encontrándose Mosquera exiliado en el Perú, entregó una copia de un Protocolo suscrito aparentemente el 11 de agosto de 1830, es decir, cuarenta años antes, entre el Perú y la Gran Colombia a Mariano Felipe Paz Soldán; el documento permaneció archivado hasta 1889, en que pasó a la cancillería peruana. Puesto que el documento aparecía suscrito por el propio Mosquera, no hay forma de negar que él mismo estuvo involucrado en su preparación. ${ }^{33}$ Es posible que Palma no haya llegado a conocer el falso Protocolo y, por lo tanto, que la opinión de Mosquera no hubiera hecho tanta fuerza en él; sin embargo, su utilización pudo haber sido menos triunfalista.

\section{Una aclaración final}

La publicación del artículo de Palma (1887) generó un extenso debate tanto en el Perú cuanto en Chile, Argentina y los países bolivarianos aunque no tanto por la parte que se refiere

33 De la carencia de validez jurídica del Protocolo el autor de estas líneas se ha ocupado extensamente en Alberto Varillas Montenegro, Perú y Ecuador. Visión actual de un antiguo conflicto, págs. 86-92. (Lima, Pontificia Universidad Católica del Perú, 1999). 
al asesinato de Monteagudo cuanto por la que se refiere a la muerte de Sánchez Carrión. En ella intervienen personajes respetables como Francisco Javier Mariátegui y Mariano Felipe Paz Soldán junto con agitadores de toda laya, llegándose, como ya se ha indicado, a quemar la efigie de Palma en un teatro de Guayaquil. En 1883, el vapuleado tradicionista metido a historiador resume su posición formulando cuatro aseveraciones:

...por más que caigan sobre mi modesta persona, a guisa de nuevo chubasco, todas las injurias del vocabulario de las desvergüenzas, insisto en creer:

Que el asesinato de Monteagudo fue crimen político, y no obra de la casualidad;

Que Bolívar alcanzó a descubrir la cabeza que concibiera el plan;

Que Sánchez Carrión murió a estragos del veneno, sin que esto implique una afirmación de complicidad en Bolívar;

Que los planes de la vitalicia eran la monarquía sin la palabra monarca. $[\ldots]^{34}$

Con respecto a la primera de sus aseveraciones, descartado el robo como móvil, hay razones como para suponer que el asesinato de Monteagudo fue un crimen político (la Logia republicana para prevenir un renacimiento del monarquismo o los españoles a quienes maltrató en exceso), ${ }^{35}$ aunque no es posible descartar totalmente que pudiera haber sido consecuencia de la permanente vida galante del coronel argentino, lo cual hasta hoy no se ha estudiado. Nada hay que vincule a Sánchez Carrión con este delito y en su artículo

34 Id. pág. 210. Se ha suprimido el quinto enunciado de Palma, que es una consideración carente de importancia sobre la relación entre Bolívar y el Perú, puesto que distraería la atención del lector.

35 La tesis de Paz Soldán de que el crimen fue fruto de la casualidad parecería no tener mayor asidero. 
histórico el propio Palma ya había advertido que “...quizás Sánchez Carrión fue una víctima inocente; tal vez no conoció siquiera el plan de asesinato tramado por algunos de sus compañeros, asustadizos o impacientes."

A propósito de la segunda de sus aseveraciones, Bolívar pudo haber llegado a descubrir al autor intelectual del crimen tanto por intermedio de Candelario Espinoza cuanto por alguna otra fuente que hasta hoy nadie ha sugerido. A favor de la consideración de Espinoza como fuente aparece la reunión que ambos sostuvieron el 30 de enero de 1825: cabe la posibilidad de que Espinoza haya formulado una confesión verosímil y que, debido a ella, un año después el Libertador haya conmutado la pena de muerte a la que se le había condenado. A favor de esta presunción también existen los testimonios de los secretarios de Bolívar, Espinar y Mosquera, guardados en silencio respectivamente durante los siguientes treinta y cincuenta años posteriores al crimen. En su artículo, Palma pudo haber tenido razón.

Con respecto a la tercera de sus afirmaciones, es posible que Palma haya seguido con demasiado rigor al imaginario popular, que con alguna frecuencia acepta tesis rodeadas de dramatismo así no sean rigurosamente verosímiles. Los últimos tres meses de vida de Sánchez Carrión dan testimonio tanto de que no gozaba de buena salud cuanto de su necesidad de cambio de clima y reposo: suponer que el veneno que se le proporcionó en febrero habría de tener efecto en junio, cien días después, es un aseveración difícil de sostener. Más razonable pareciera el resultado de la autopsia practicada por Cayetano Heredia, de la cual informa Heres a Bolívar. Finalmente, el propio Palma advierte que en momento alguno ha atribuido a Bolívar ser cómplice del envenenamiento de Sánchez Carrión. 
La última de las afirmaciones de Palma puede tener sabor extraño para el lector de hoy, cuando el Perú se aproxima al bicentenario de su Independencia. Resultaría redundante indicar que tanto San Martín cuanto Bolívar eran partidarios de la Independencia sin que esto signifique que comulgaban con el régimen republicano pues resultaban testigos de excepción de lo que venía ocurriendo en los mismos años en las Provincias Unidas de la Plata, Chile y la Gran Colombia. El régimen monárquico para las posesiones españolas recién liberadas en América no había sido desechado: en las Provincias Unidas de la Plata, su Director Supremo Juan Martín de Pueyredón comisiona en 1814 a Bernardino Rivadavia y Manuel Belgrano para que viajen a Europa en busca de un candidato a la monarquía; en Chile, Bernardo O’Higgins encarga a Antonio José de Irisarri igual viaje con propósitos parecidos; en México, el texto que redacta Itúrbide para su juramento como emperador contiene la frase “...conservar el gobierno monárquico moderado del Imperio”. Por último, debe tenerse presente que en Europa la Santa Alianza, que en un momento aglutinó a todas las grandes potencias del Antiguo Continente, se constituyó con el propósito de mantener vigentes los acuerdos adoptados en el Congreso de Viena (1815). Lo que indica que el sistema monárquico es el que imperaba en el mundo de aquellos años. Las instrucciones dadas por el Consejo de Estado a Juan García del Río y Diego Paroissien el 24 de diciembre de 1821 no dejan lugar a dudas: “...Para conservar el orden interno del Perú y a fin de que este Estado adquiera la respetabilidad exterior de que es susceptible, conviene el establecimiento de un gobierno vigoroso, el reconocimiento y la alianza o protección de una de las potencias de primer orden en Europa"; tampoco deja lugar a duda alguna el artículo $77^{\circ}$ de la Constitución de 1826: "El ejercicio del Poder Ejecutivo reside en un Presidente Vitalicio..." que concuerda con el artículo $1^{\circ}$ del Decreto de 30 de noviembre de 1826, aprobado cuando Bolívar ya llevaba tres meses ausente del Perú: 
Con arreglo a la voluntad nacional altamente pronunciada, el proyecto de Constitución sometido a la sanción popular en $1^{\circ}$ de Julio último, es la ley fundamental del Estado, y S. E., el Libertador Simón Bolívar, el presidente vitalicio de la República, bajo el hermoso título de padre y salvador del Perú que le dio la gratitud del Congreso.

Por lo tanto, tiene plena validez la cuarta de las aseveraciones de Palma en el sentido de que lo que perseguía Bolívar era“...la monarquía sin la palabra monarca".

\section{Recapitulación.}

De la revisión del artículo histórico de Palma se pueden extraer algunas conclusiones. El autor no muestra especial simpatía por Bolívar aunque tampoco se presenta como especial partidario de San Martín, aunque reconoce los méritos particulares de ambos. Las preferencias del tradicionista oscilan entre los dos personajes principales: simpatiza con Monteagudo por su prestancia y su capacidad organizativa, la que destaca, pero siente igual aprecio por Sánchez Carrión por su indoblegable vocación republicana: curiosamente se siente atraído tanto por el hombre de mundo que fue Monteagudo cuanto por el austero combatiente liberal que fue Sánchez Carrión. A lo largo de toda la obra, en momentos de juzgar a estos dos personajes, Palma logra mostrarse equilibrado y solo en unos pocos momentos pierde la objetividad. ${ }^{36}$ Lo que resulta evidente es que la pluma de Palma se prestaba más para la redacción de sus sabrosas tradiciones que para textos rigurosamente históricos.

36 Por ejemplo, cuando se refiere a la vigorosa salud de Sánchez Carrión o cuando pareciera atribuir, sin mayor explicación, a Monteagudo por “...la expulsión violenta de más de cuatro mil peninsulares, muchos de los cuales fueron víctimas de la salvaje crueldad del capitán del bergantín Pacífico". 
Por último, no debe llamar la atención que a fines de la década de 1870 se hubiera producido una polémica internacional a propósito de un texto como el de Palma, sin especial relieve, que aparece escondido dentro de una colección de documentos que forma parte de una docena de volúmenes. La viva indignación que en el medio culto de la región produjo efectivamente la difusión del texto de Palma determinó la aparición de beligerantes bolivaristas en media docena de países lo que produjo una curiosa consecuencia: la discusión quedó centrada más en Bolívar y su obra (inclusive en las campañas que había llevado a cabo antes de llegar al Perú) que en la posibilidad de que el Libertador hubiera estado vinculado con la muerte de Sánchez Carrión y apenas se refirió al asesinato de Monteagudo pues la documentación aducida por Palma pareció satisfacer a los lectores más acuciosos. Y así termina este curioso incidente cuya obra central no se ha publicado desde hace más de un siglo. 